Article

\title{
Improving Seasonal Land Cover Maps of Poyang Lake Area in China by Taking into Account Logical Transitions
}

\author{
Guang Yang ${ }^{1}$, Shenghui Fang ${ }^{1, *}$, Yuanyong Dian ${ }^{2}$ and Chuang Bi ${ }^{1}$ \\ 1 School of Remote Sensing Information Engineering, Wuhan University, Wuhan 430079, China; \\ yg4288721@hotmail.com (G.Y.); bichuang534@126.com (C.B.) \\ 2 Institute of Garden Forestry, Huazhong Agriculture University, Wuhan 430070, China; \\ dianyuanyong@126.com \\ * Correspondence: shfang@whu.edu.cn; Tel.: +86-27-6877-1238
}

Academic Editors: Qiming Zhou, Zhilin Li, George P. Petropoulos and Wolfgang Kainz Received: 19 August 2016; Accepted: 8 September 2016; Published: 12 September 2016

\begin{abstract}
Land cover maps are fundamental materials for resource management and change detection. Remote sensing technology is crucial for fast mapping with low cost. However, besides the inherent classification errors in the land cover products, numerous illogical transitions exist between the neighboring time points. In this study, we introduce a series of logical codes for all the land cover types according to the ecological rules in the study area. The codes represent the transformational logicality of species between different seasons. The classification performance and the codes for all the seasons are imposed on the initial land cover maps which have been produced independently by the conventional hierarchical strategy. We exploit the proposed modified hierarchical mapping strategy to map the land cover of Poyang Lake Basin area, Middle China. The illogical transitions between neighboring seasons and the accuracies based on the labeled samples are calculated for both the initial and modified strategies. The number of illogical pixels have been reduced by $13 \%-35 \%$ for different seasons and the average accuracy has been improved by $9.7 \%$ for the specific land cover maps. The accuracy of land cover changes has also presented great improvement of the proposed strategy. The experimental results have suggested the scheme is effective.
\end{abstract}

Keywords: land cover maps; illogical transitions; logical codes; ecological rules; transformational logicality; hierarchical strategy

\section{Introduction}

The Global Land Cover (GLC) is fundamental for land resource management, environmental protection, and sustainable development [1]. Land cover maps play an important role in a variety of applications [2] and remote sensing techniques have been effective for land cover mapping [3,4]. Various global land cover products such as the International Geosphere-Biosphere Program Data and Information System's (IGBP-DIS) land cover product [5], the Global Land Cover database for the year 2000 (GLC2000) [6], University of Maryland Global Land Cover Classification (UMD GLCC) [7], Moderate Resolution Imaging Spectroradiometer (MODIS) land cover (MOD12Q1) [8], MODIS land cover (MCD12Q1) [9], and GlobCover [10] have been frequently-used materials [11-17]. The development of satellite technology makes it possible to acquire sufficient remote sensing data with finer spatial resolution. As a result, Finer Resolution Observation and Monitoring of Global Land Cover (FROM-GLC) has been produced at a resolution of $30 \mathrm{~m}[18,19]$.

The mapping of regional land cover is imperative, which is of great help to the regional construction and management $[20,21]$. The multi-temporal land cover maps make especially great 
contributions in acquiring the long-term land cover information [22,23]. The post-classification comparison effectively examines the changes between the land cover maps with different time points, which makes it possible to quickly assess the spatial and temporal dynamics of the study areas [24,25]. A study has suggested that a regionally focused land cover map would, in fact, be more accurate than extracting the same region from a globally produced map [26]. Nowadays, it is quite convenient to acquire highly temporal remote sensing images for a certain area, which makes it feasible to produce regional land cover maps quarterly.

A common problem has been generated between various land cover products. Different land cover products have shown great inconsistency and the disagreements increase with finer land cover types $[27,28]$, which has brought difficulties in the application. It is not easy for users to choose the credible results among different products. Meanwhile, a number of illogical land cover transitions have been discovered in the same land cover products at different dates [29-32]. The illogical transitions are recognized as the land cover changes within a period of time which are impossible to be caused by natural changes or human activities. The transitions generally exceed the scope of rational land cover changes, so the land cover classification results with illogical disagreements must be wrong at a certain time point. The differences of classifiers, mapping strategies, input data, and discrepancies in species definition all lead to the illogical transitions within a given time period [20].

However, only a few studies have taken into account the logical correlation of the land cover maps at different dates. Studies associated with change detection have discovered large areas of illogical transitions in land cover maps [31-34], but the information of the land cover changes has not been effectively employed to refine the multi-temporal land cover maps. Recent studies have enhanced the quality of MODIS global land cover products by reducing illogical transitions [35,36]. Maps for each single year have been produced not only through the data from that year, but also from the preceding and subsequent years. These approaches have been focused on improving annual products with coarse resolution. However, the seasonal land cover maps can provide the intra-annual variability of land cover types dominated by vegetation with marked phenology [37]. In addition, the post-classification framework has taken into account the temporal-spatial correlation, but has not considered the classification performance of different time points, which should be an important indicator of post-classification refinement.

In this study, we have exploited multi-source remote sensing images to generate seasonal land cover maps. The labels of the pixels covered by multiple images have been decided by voting, and a hierarchical strategy has been employed to generate the land cover maps in different levels. We have further modified the results of all the seasons by taking into account the logical transitions and the classification performance of all the land cover types in different seasons. A series of predetermined logical codes which stand for the rationality of land cover transitions have been applied to the hierarchical strategy. We have employed the proposed modified hierarchical mapping strategy to produce the land cover maps of the middle and northern of Poyang Lake Basin area, Middle China. After the modification procedure, the rates of disagreements between land cover maps with the adjacent time points have been reduced significantly with an evident increase of the accuracy.

The remainder of the paper is organized as follows: Section 2 introduces the study area. Section 3 introduces the experimental materials, the initial mapping strategy and the modified scenario based on the logical transitions. Section 4 gives the mapping results in detail by the novel strategy. The initial and modified land cover maps will be statistically compared and discussed in this section. Finally a general summary of the paper will be presented in Section 5.

\section{Study Area}

The study area is located in the middle and north of the Poyang Lake Basin, Middle China. Its location is presented in Figure 1. The climate features a temperate ecosystem and subtropical ecosystem. The area is mainly covered by the croplands, forests, and water body. The main crop types comprise paddy and oilseed rape. The two kinds of crops are often planted in rotation in this area. 


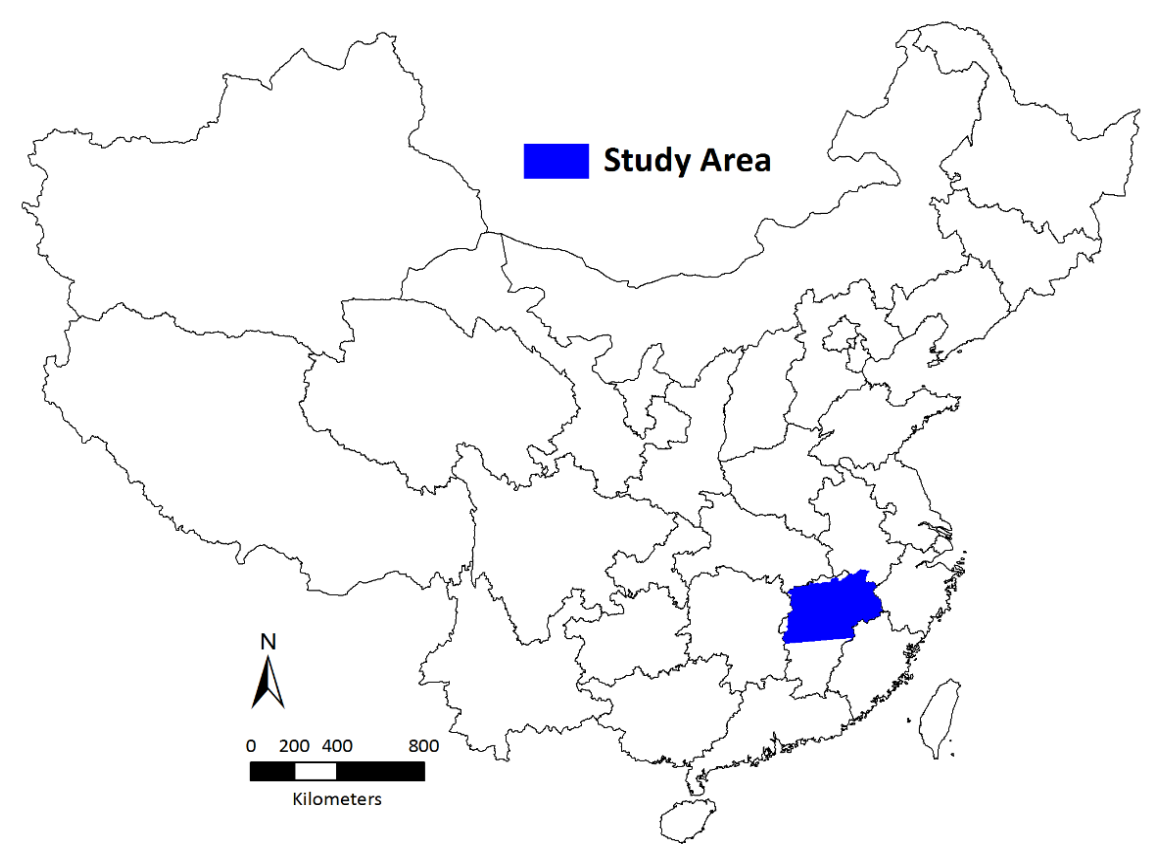

Figure 1. Study area.

\section{Methodology}

\subsection{Materials}

Huan Jing Charge-coupled Device (HJ-CCD) and Landsat 8 image data in 2014 are used as input for land cover mapping. The images, all covering the study site, are georeferenced and the resolution is $30 \mathrm{~m}$. The multi-source images are divided into four parts according to the date range by seasons. We define January-March as Season 1 (nine images), April-June as Season 2 (nine images), July-September as Season 3 (eight images) and October-December as Season 4 (seven images). The partition refers to the natural changes of the main vegetation types. The initial mapping procedure is carried out respectively for each season.

The reference data are mainly collected by human interpretation from the images in Google Earth and field survey in 2014. In all, 7392 locations of ground truth in terms of class label, longitude, and latitude are collected for each season. The samples are used for both training and accuracy evaluation. The samples are initially represented by subclasses.

\subsection{Voting Scenario}

A single satellite sensor provides insufficient remote sensing data for seasonal land cover mapping problems. The availability of multi-source remote sensing data makes it imperative to combine information from different sources to produce land cover maps [38-41]. However, multi-source images generally have different band compositions and different land cover ranges. Besides, they can also be acquired in different time points or seasons.

In this study, we exploit the voting scenario to consider the classification results of multiple-source images. For each image in a certain temporal and spatial range, the classification results are yielded by support vector machine (SVM) [42,43]. If multiple images cover the same area in a certain season, the results from multi-source images will be synthetically determined by a voting scheme. The class label with the highest votes is decided to be the resultant label. If different labels have the same votes, the classification accuracies will be taken into account. The class label with the highest average user's accuracy (UA) will be chosen. In a word, the classification process is carried out on each image, while the resultant class labels are synthetically decided by the classification results of multi-source data. Figure 2 illustrates the determination of class labels for one time point (one season) by multiple 
images and the voting scenario. A, B, C represent three images in one season. Digit 1 and 2 represent the class labels of the three sample pixels. PA1, PB2, and PC2 stand for the classification accuracy of the classes in the corresponding images. The resultant labels of the three pixels covered by different numbers of images are decided by the voting scenario. We can, further, acquire the performance of each class for each season by the strategy.

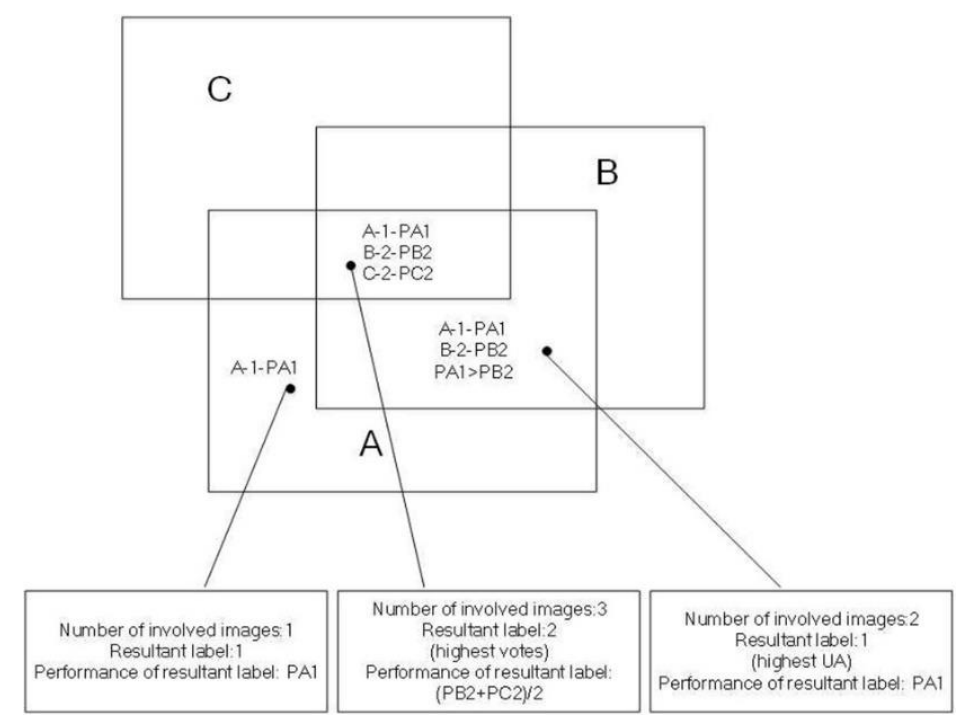

Figure 2. Voting scenarios.

\subsection{Hierarchical Classification Strategy}

A number of land cover species have clear hierarchical system [10,44]. For example, the forest land is usually divided into broad-leaved forest and coniferous forest, while in more detail, we have evergreen broad-leaved forest, evergreen coniferous forest, deciduous broad-leaved forest, and deciduous coniferous forest like in IGBP. We exploit the hierarchical strategy from top to bottom $[45,46]$. The mapping work complies with the previously determined classification scheme according to the physical truth of the study area. The classification scheme for land cover types is listed in Table 1. We first classify the land cover types focusing on the primary (Level-1) classes. Based on the Level-1 maps, the specific (Level-2) classes belonging to their Level-1 classes will be classified respectively. Figure 3 illustrates the hierarchical mapping strategy for a certain time point.

Table 1. Classification scheme for land cover types.

\begin{tabular}{cc}
\hline Level-1 Classes & Level-2 Classes \\
\hline Cropland & Paddy \\
& Oilseed rape \\
Other crops \\
Forest land & $\begin{array}{c}\text { Broad-leaved forest } \\
\text { Coniferous forest } \\
\text { Lakes } \\
\text { Water body }\end{array}$ \\
Bare land & Rivers \\
& Terranora \\
& Biver/lake bed \\
Artificial cover & \\
Clouds & \\
\hline
\end{tabular}




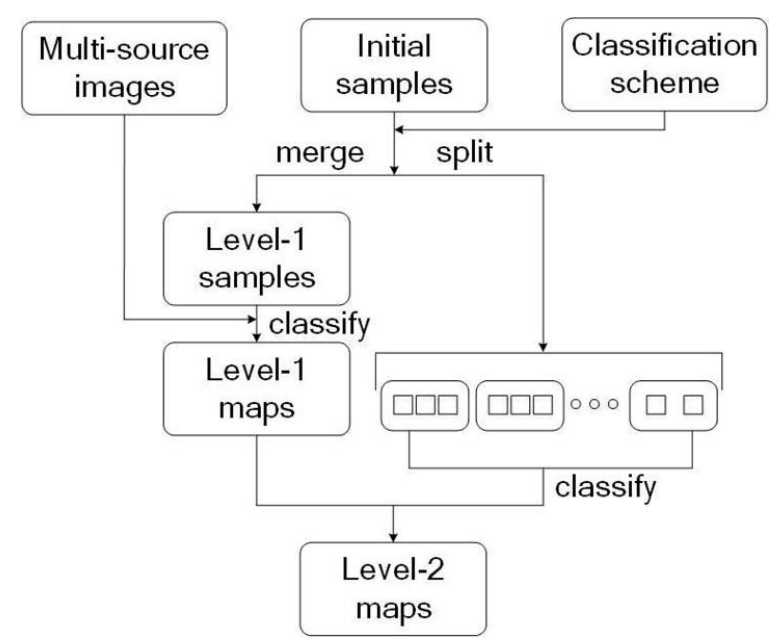

Figure 3. Illustrating the hierarchical mapping strategy.

The initial samples are automatically merged and divided according to the classification scheme. As a result, samples at both levels are generated. The Level-1 maps are produced by the classification strategy and Level-1 samples. The Level-2 samples which represent the specific land cover types are divided into various groups and each group belongs to a Level-1 class. The pixels in the Level-1 maps will be reclassified respectively based on the Level-2 samples, unless the Level-1 class does not have subclasses, such as "artificial cover" and "clouds". The Level-1 maps will be replaced by the specific classification results respectively, and finally the Level-2 maps are produced.

\subsection{Post-Classification Refinement}

According to [47], the ground truth data is of great importance in the post-classification refinement. In this study, we first employ all the ground truth data (including training samples and other reference data) to refine the initial land cover maps. All the misclassified pixels among the ground truth are corrected. Then, a modification process according to the logical transitions is carried out. The details are presented in the following.

\subsubsection{Four-Digit Codes for Seasonal Transitions of Land Cover Types}

Unlike the annual land cover products, the logical correlation of the seasonal transitions shows periodic properties. Products of the last time point (the last season) have the temporal relationship with the beginning time point (the first season). We establish a series of codes containing all the logical and illogical transitions for land cover types at different levels (Tables 2 and 3).

Table 2. Four-digit codes for Level-1 classes.

\begin{tabular}{ccccccc}
\hline Class label & Cropland & Forest Land & Water Body & Bare Land & Artificial Cover & Clouds \\
\hline Cropland & 1111 & 1221 & 2222 & 1111 & 2222 & 1111 \\
Forest land & 1111 & 1111 & 2222 & 1111 & 2222 & 1111 \\
Water body & 1111 & 2222 & 1111 & 1111 & 222 & 1111 \\
Bare land & 1111 & 1221 & 1111 & 1111 & 1111 & 1111 \\
Artificial cover & 2222 & 2222 & 2222 & 1111 & 1111 & 1111 \\
Clouds & 1111 & 1111 & 1111 & 1111 & 1111 & 1111 \\
\hline
\end{tabular}


Table 3. Four-digit codes for Level-2 classes.

\begin{tabular}{|c|c|c|c|c|c|c|c|c|c|c|}
\hline \multirow{2}{*}{$\begin{array}{l}\text { Level-1 } \\
\text { Level-2 }\end{array}$} & \multicolumn{3}{|c|}{ Cropland } & \multicolumn{2}{|c|}{ Forest Land } & \multicolumn{3}{|c|}{ Bare Land } & \multicolumn{2}{|c|}{ Water Body } \\
\hline & PD $^{1}$ & OR $^{2}$ & $\mathrm{OC}^{3}$ & $\mathrm{BL}^{4}$ & $\mathrm{CF}^{5}$ & $\mathrm{TN}^{6}$ & $\mathrm{DR}^{7}$ & BS $^{8}$ & LK $^{9}$ & RV ${ }^{10}$ \\
\hline PD & 2112 & 2211 & 2211 & & & & & & & \\
\hline OR & 1122 & 1221 & 1122 & & & & & & & \\
\hline OC & 1122 & 2211 & 1111 & & & & & & & \\
\hline BL & & & & 1111 & 2222 & & & & & \\
\hline CF & & & & 2222 & 1111 & & & & & \\
\hline $\mathrm{TN}$ & & & & & & 1111 & 2222 & 1111 & & \\
\hline DR & & & & & & 2222 & 1111 & 1111 & & \\
\hline BS & & & & & & 1111 & 2222 & 1111 & & \\
\hline LK & & & & & & & & & 1111 & 2222 \\
\hline RV & & & & & & & & & 2222 & 1111 \\
\hline
\end{tabular}

The rationality of transitions are described by a series of four-digit codes, which stand for the transformational possibility of every two land cover types between the neighboring seasons. The codes at any location of the table stand for the possibility of the transitions from the species of the row heading to the species of the column heading. For example, digit "1" represents logical or possible transitions and digit "2" means illogical or impossible transitions. We define illogical transitions that are unlikely to happen within certain neighboring seasons. The transitions defined as "logical" can be caused by human activities or natural changes within a season. The first digit stands for the transitions from the first season to the second season, while the fourth digit stands for the transitions from the last season to the first season. For instance, water body and artificial cover are not likely to convert reciprocally in each neighboring season, so the code associated with the two land cover types is "2222". Paddy generally grows from May to October and oilseed rape from September to June (next year) in Middle China. As a result, it is impossible for oilseed rape to convert into paddy from the third season to the fourth season. Consequently, the code of the transition is " 2 ". It should be noted that the codes are predetermined and operant for the study region, at most for the type of the ecological system.

We establish the codes for both Level-1 and Level-2 classes, which makes it suitable for hierarchical strategy. The modified hierarchical mapping strategy will be interpreted in the following.

\subsubsection{Rules for Seasonal Land Cover Mapping}

The resultant labels of the initial land cover maps should be modified at the occurrence of any illogical transitions between neighboring seasons. According to the voting scenario, we get the classification accuracy of all the classes for each season. The modification rules are based on the classification performance of all the land cover types in different seasons. The initial label in a certain season with lower user's accuracy will be transformed into that with higher user's accuracy in its neighboring season. The following cases will further explain how we modify the seasonal land cover types using the codes defined above.

(1) If the transformational codes of the land cover type A to B is "2222" (such as water body-artificial cover), the transition from A to B is unlikely to happen within one year. As a result, if a certain pixel is predicted as either A or B in all seasons, labels for the land cover types have to be unified by voting scheme between different seasons. If they have the same votes, the label with the higher average user's accuracy will be selected.

(2) The four-digit codes initially reflect the logical transitions between two land cover types. The codes should be composited if the initial class labels for a pixel location in four seasons have more than two kinds of land covers. For instance, the codes for a pixel initially labeled as "terranora-terranora-dry river/lake bed-bare soil" for four seasons is " 1211 " according to Table 3. The codes are empty if the transitions between Level-2 classes are beyond superclass, for example 
"paddy-bare soil". In addition, labels of these pixels should not be modified beyond superclass in any case.

(3) The user's accuracy is taken into account at the occurrence of consecutive contradiction. If consecutive contradiction encounters, such as "1221", then the user's accuracy of the pixel in the second and fourth season should be compared. The computation and modification procedure run from the side of higher accuracy.

The judgement just works once for each season because a recursive procedure may lose time efficiency, generate ambiguity, and influence the right results to a certain degree.

\subsubsection{Modified Hierarchical Mapping Strategy According to Logical Transitions}

Based on the initial mapping strategy featuring voting scenario and hierarchical scheme, we further design a modified approach, taking into account the logical transitions. The codes and rules for seasonal transitions are attached to the initial strategy. Two major steps explain the whole working flow.

The first step is focused on Level-1 maps. The codes and classification performance for the Level-1 classes are imposed on the initial Level-1 maps which are produced by the initial mapping strategy. According to the rules explained above, the modified Level-1 maps are produced after the modification procedure.

The second step is focused on Level-2 maps. Based on the modified Level-1 maps and groups of Level-2 samples, the initial Level- 2 maps are generated through the respective classification procedure. Finally, the rules for the Level-2 classes work on the initial Level-2 maps and then the modified Level-2 maps are produced. Consequently, the transformational rules are employed to improve the land cover maps at both levels. We do not take into account the transitions beyond superclass, since the modification procedure for Level-1 maps has reduced the illogical transitions of Level-1 classes as many as possible even if a small portion of illogical transitions may still exist. The illustration of the modified hierarchical mapping strategy is presented in Figure 4.

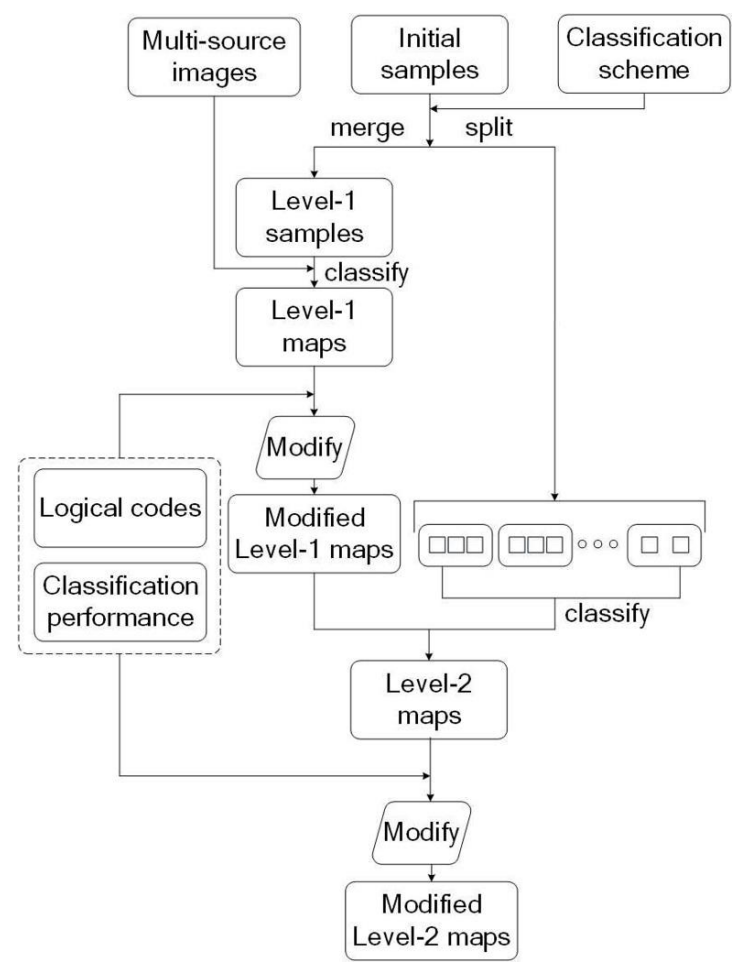

Figure 4. Modified hierarchical mapping strategy. 
The import of transformational rules is suitable for hierarchical mapping strategy when the logical codes are divided into different levels. Meanwhile, the modification for different levels does not conflict because the adjustment is carried out at each level separately and orderly. Moreover, the added work needs little calculation because it is an amendatory procedure considering temporal relationship without circulation.

\section{Results and Discussion}

\subsection{Land Cover Maps for Different Seasons}

The seasonal land cover maps of Poyang Lake Basin are produced through the methodology specified above. Figure 5 presents the land cover maps containing the main land cover types. Figure 5a-d present the initial results and Figure 5e-h present the results after the modification procedure. The initial land cover maps for different seasons are produced respectively through the voting scenario and hierarchical strategy, while the modification procedure is carried out simultaneously between different seasons, thus generating the modified land cover maps. In addition, a few pixels are corrected by the reference data. A number of pixels have been changed by the modification procedure according to the overall maps, especially for crop species, forest cover, and water body.
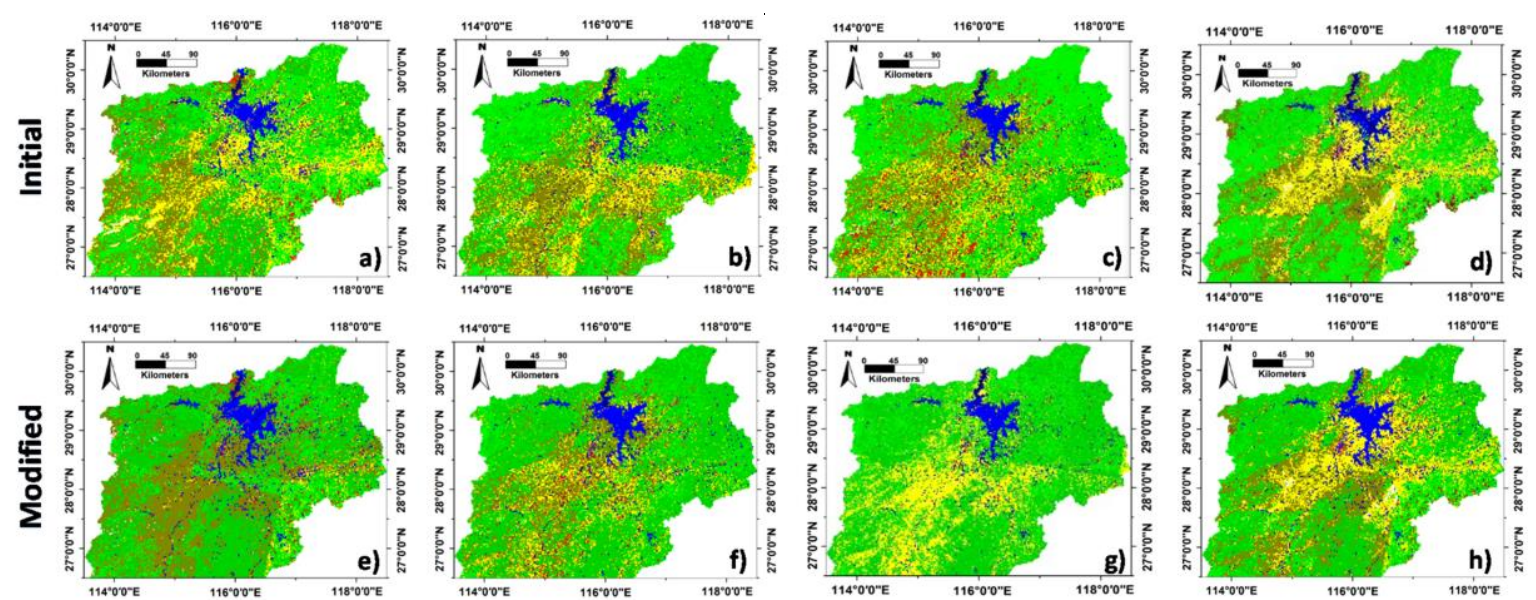

Season 2

Season 3

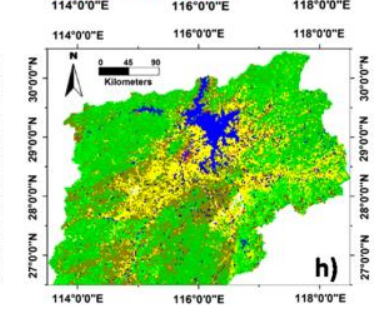

Season 4

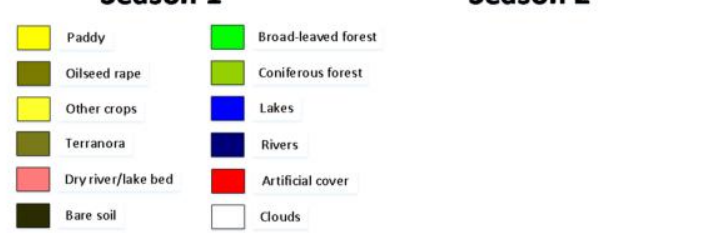

Figure 5. Land cover maps of Poyang Lake Basin for different seasons. (a-d) present the results produced by the initial strategy; $(\mathbf{e}-\mathbf{h})$ present the results after the modification procedure.

Two sites are presented in Figure 6 focusing on details. Many illogical transitions have been modified and a number of land cover types have changed. In the initial land cover maps, some illogical transitions among crops, water body, and forests occur in Figure 6a. The renewed maps have significantly improved the results. As mentioned above, serious errors are quite likely to happen in a certain time point owing to the unstable quality of the input data and the environmental factors. The initial result in the first season in Figure $6 \mathrm{~b}$ is just the case. There exists substantial discrepancy between the first season and other seasons, like the missing water body in the first season, which indicates obvious classification errors in the first season. After being modified considering the logical transitions between all the seasons, the result of the location in the first season has been improved. 


\subsection{Accuracy Evaluation}

In this study, we exploit two scenarios to evaluate the products by the reference data. One is the overall accuracy (OA) for the year and the other is the accuracy evaluation in terms of land cover changes for every two adjacent seasons.
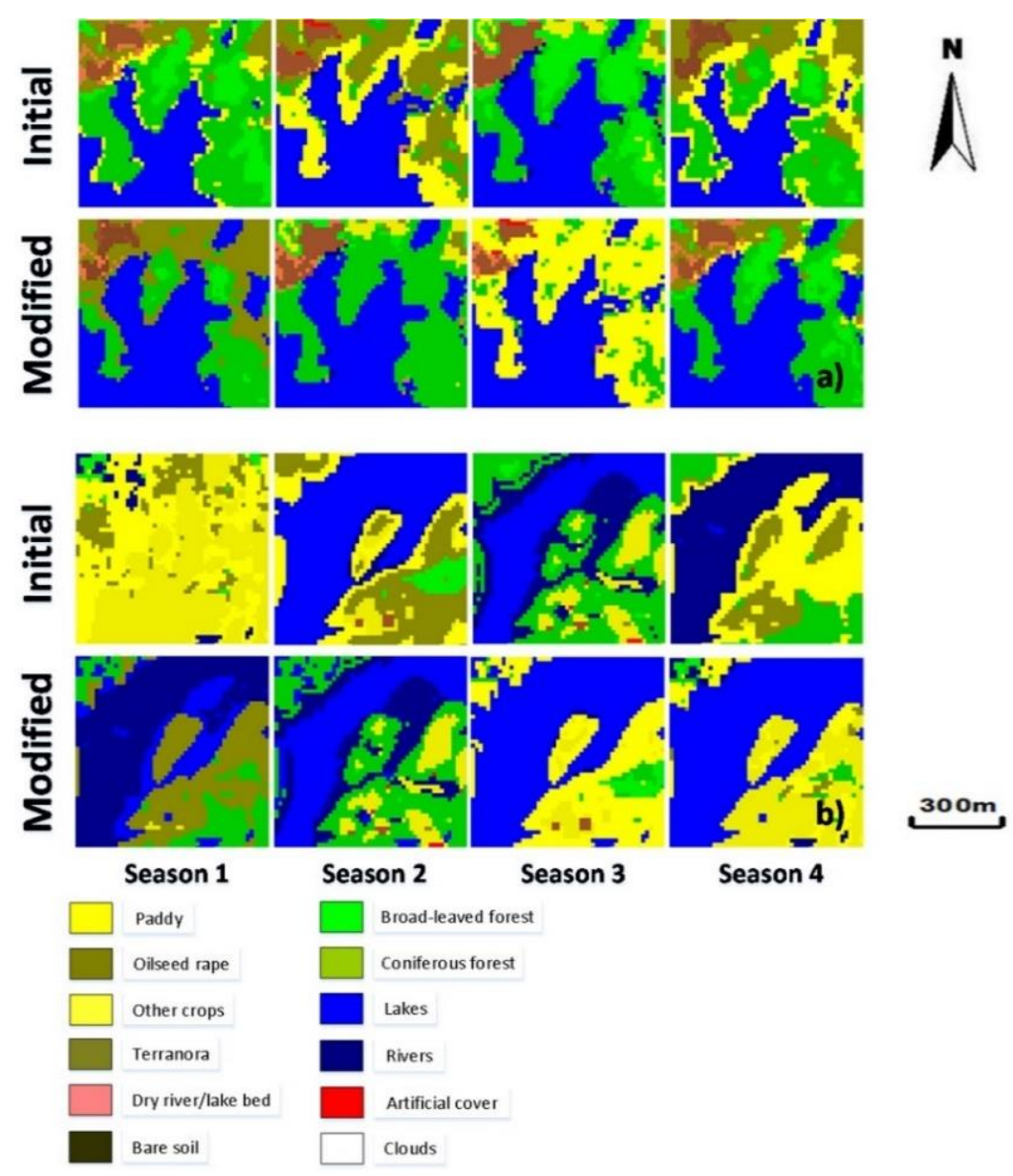

Figure 6. Details of land cover maps (a,b) details for different locations.

\subsubsection{Overall Classification Accuracy}

Table 4 lists the average accuracies of four seasons by the labeled samples (In each season, 1000 test samples are randomly collected among the labeled pixels for each Level-1 class. The numbers of the correct pixels are round-off values. Accuracies of the crops are calculated only for growing seasons). The boldfaced values represent Level-1 classes and the others represent Level-2 classes. The main land cover types with subclasses are listed and the clouds and artificial cover are omitted because of small land cover areas and few labeled samples. The total number of the correctly labeled samples of subclasses is smaller than that of their superclass, since the misclassification exists between subclasses. Accuracies of both strategies are presented in the table. The proposed strategy significantly outperforms the initial strategy from the perspective of accuracy. The accuracies have been greatly improved in many land cover types, such as water body, bare land, and specific croplands with clear phenological characters. The statistics show 8.3\% increase for Level-1 classes and 9.7\% for Level-2 classes in accuracy, which suggests great effectiveness of the modified approach for land cover mapping. 
Table 4. Average classification accuracy of all seasons by both strategies.

\begin{tabular}{cccccc}
\hline \multirow{2}{*}{ Class } & \multirow{2}{*}{ Reference Pixels } & \multicolumn{2}{c}{ Initial } & \multicolumn{2}{c}{ Modified } \\
\cline { 3 - 6 } & & Correct & PA $^{\mathbf{1}}$ & Correct & PA \\
\hline Cropland & $\mathbf{1 0 0 0}$ & $\mathbf{8 7 2}$ & $\mathbf{0 . 8 7 2}$ & $\mathbf{9 1 6}$ & $\mathbf{0 . 9 1 6}$ \\
Paddy & 332 & 224 & 0.675 & 272 & 0.819 \\
Oilseed rape & 337 & 226 & 0.671 & 278 & 0.825 \\
Other crops & 331 & 241 & 0.728 & 245 & 0.74 \\
Forest & $\mathbf{1 0 0 0}$ & $\mathbf{9 0 7}$ & $\mathbf{0 . 9 0 7}$ & $\mathbf{9 8 0}$ & $\mathbf{0 . 9 8 0}$ \\
Broad-leaved forest & 528 & 415 & 0.786 & 444 & 0.841 \\
Coniferous forest & 472 & 351 & 0.744 & 420 & 0.89 \\
Water body & $\mathbf{1 0 0 0}$ & $\mathbf{9 3 8}$ & $\mathbf{0 . 9 3 8}$ & $\mathbf{9 9 0}$ & $\mathbf{0 . 9 9 0}$ \\
Lakes & 484 & 441 & 0.911 & 456 & 0.942 \\
Rivers & 516 & 417 & 0.808 & 479 & 0.928 \\
Bare land & $\mathbf{1 0 0 0}$ & $\mathbf{6 6 0}$ & $\mathbf{0 . 6 6}$ & $\mathbf{8 2 1}$ & $\mathbf{0 . 8 2 1}$ \\
Terranora & 343 & 210 & 0.612 & 217 & 0.633 \\
Dry river/lake bed & 308 & 151 & 0.49 & 246 & 0.799 \\
Bare soil & 349 & 222 & 0.636 & 232 & 0.665 \\
Level-1 & 4000 & 3377 & OA $^{2}=0.844$ & 3707 & OA $=0.927$ \\
Level-2 & 4000 & 2898 & OA $=0.725$ & 3289 & OA $=0.822$ \\
\hline
\end{tabular}

${ }^{1}$ Producer's accuracy; ${ }^{2}$ Overall accuracy.

\subsubsection{Land Cover Change Accuracy}

Owing to the fact of crop rotation, we cannot acquire the accuracies of all the land cover types for each season. Lack of labeled samples for artificial cover and clouds makes it hard to effectively evaluate the accuracies for these classes. Furthermore, land cover maps from different seasons reflect more differences, especially for the cropland. In this study, we also assess the products by land cover changes. We do not care about the land cover types. Instead, only the land cover changes are considered. We adopt the technique mentioned in [48] to calculate the accuracy of land cover changes.

Suppose A, B, C, D respectively stand for the number of changed pixels by reference data and changed pixels by our results; unchanged pixels by reference data and changed pixels by the products; changed pixels by reference data and unchanged pixels by the products; unchanged pixels by reference data and unchanged pixels by the products. The predicted positive value $\left(U_{1}\right)$ and the predicted negative value $\left(U_{2}\right)[49]$ are recognized as functions of the classifier ability and accuracy. We calculate $U_{1}$ and $U_{2}$ by Equation (1) and Equation (2)

$$
\begin{aligned}
& U_{1}=\frac{S_{1} \theta}{S_{1} \theta+\left(1-S_{2}\right)(1-\theta)} \\
& U_{2}=\frac{S_{2}(1-\theta)}{S_{2}(1-\theta)+\left(1-S_{1}\right) \theta}
\end{aligned}
$$

where

$$
\begin{gathered}
S_{1}=\frac{A}{A+C} \\
S_{2}=\frac{D}{B+D} \\
\theta=\frac{A+C}{A+B+C+D}
\end{gathered}
$$

1000 locations are randomly selected from the reference data. The same locations are extracted from the results. We first get a suite of statistics according to the reference data and the results for both the initial and the modified maps (Table 5). The performance of both strategies is derived from the values in Table 5. The results are listed in Table 6. The values of $U_{1}$ and $U_{2}$ show a discernable increase in the accuracies of land cover changes. 
Table 5. Statistics by reference data and the results.

\begin{tabular}{ccccccccc}
\hline \multirow{2}{*}{ Seasons } & \multicolumn{4}{c}{ Initial } & \multicolumn{5}{c}{ Modified } \\
\cline { 2 - 9 } & A & B & C & D & A & B & C & D \\
\hline $1-2$ & 5 & 170 & 35 & 790 & 29 & 29 & 11 & 931 \\
$2-3$ & 97 & 143 & 56 & 704 & 118 & 90 & 35 & 757 \\
$3-4$ & 75 & 186 & 49 & 690 & 80 & 106 & 44 & 770 \\
$4-1$ & 5 & 160 & 40 & 795 & 25 & 40 & 20 & 915 \\
\hline
\end{tabular}

Table 6. Land cover change accuracies for different seasons.

\begin{tabular}{ccccc}
\hline \multirow{2}{*}{ Seasons } & \multicolumn{2}{c}{ Initial } & \multicolumn{2}{c}{ Modified } \\
\cline { 2 - 5 } & $\mathbf{U}_{\mathbf{1}} \mathbf{( \% )}$ & $\mathbf{U}_{\mathbf{2}} \mathbf{( \% )}$ & $\mathbf{U}_{\mathbf{1}} \mathbf{( \% )}$ & $\mathbf{U}_{\mathbf{2}} \mathbf{( \% )}$ \\
\hline $1-2$ & 2.86 & 95.76 & 50.00 & 98.83 \\
$2-3$ & 40.42 & 92.63 & 56.73 & 95.58 \\
$3-4$ & 28.74 & 93.37 & 43.10 & 94.59 \\
$4-1$ & 3.03 & 95.21 & 38.46 & 97.86 \\
\hline
\end{tabular}

\subsection{Discussion}

\subsubsection{Statistics and Comparison}

We count the inconsistent pixels between all the neighboring seasons. Among these inconsistent pixels, we further calculate the illogical numbers according to the physical truth of the region. The statistical results of the initial maps are presented in Table 7. Tremendous numbers of inconsistent pixels exist between neighboring seasons and there are also numerous illogical transitions. A similar phenomenon has been found in other studies [11,50-52]. Table 8 presents the numbers and rates of inconsistent pixels generated by the modified maps taking into account the temporal transitions. With the help of the logical constraint, both the inconsistent rates and the illogical transitions are greatly reduced. Tables 9 and 10 provide the improvements in detail. The illogical transitions associated with the main land cover for different strategies are presented. Plenty of illogical transitions happen to the cropland and forest land. The wide coverage, the discrepancy in the quality of multi-temporal images, and the confusion of subclasses all lead to the phenomenon. With the constraints of the carefully defined ecological rules, the illogical transitions of all the land cover types are substantially cut down.

Table 7. Inconsistent pixel statistics by the initial maps.

\begin{tabular}{ccccc}
\hline Seasons & Inconsistent Pixels & Inconsistent Rate & Illogical Pixels & Illogical Rate \\
\hline $1-2$ & $85,820,425$ & $65.59 \%$ & $46,926,473$ & $35.86 \%$ \\
$2-3$ & $91,262,718$ & $69.75 \%$ & $69,584,679$ & $53.18 \%$ \\
$3-4$ & $82,361,668$ & $62.75 \%$ & $64,566,765$ & $49.35 \%$ \\
$4-1$ & $68,209,669$ & $52.13 \%$ & $38,203,436$ & $29.20 \%$ \\
\hline
\end{tabular}

Table 8. Inconsistent pixel statistics by the modified maps.

\begin{tabular}{ccccc}
\hline Seasons & Inconsistent Pixels & Inconsistent Rate & Illogical Pixels & Illogical Rate \\
\hline $1-2$ & $48,668,565$ & $37.20 \%$ & $15,142,276$ & $11.58 \%$ \\
$2-3$ & $62,264,436$ & $47.59 \%$ & $24,638,692$ & $18.83 \%$ \\
$3-4$ & $60,632,812$ & $46.34 \%$ & $36,109,713$ & $27.60 \%$ \\
$4-1$ & $44,831,920$ & $34.26 \%$ & $21,048,549$ & $16.09 \%$ \\
\hline
\end{tabular}


Table 9. Illogical pixels associated with four land cover types for the initial maps.

\begin{tabular}{ccccc}
\hline Seasons & Cropland & Forest Land & Water Body & Bare Land \\
\hline $1-2$ & $35,315,244$ & $22,981,725$ & $2,437,095$ & 447,586 \\
$2-3$ & $54,640,786$ & $46,294,331$ & $1,938,652$ & 327,609 \\
$3-4$ & $47,026,937$ & $38,635,981$ & $2,154,171$ & 835,130 \\
$4-1$ & $20,192,017$ & $18,062,564$ & $1,953,331$ & 535,948 \\
\hline
\end{tabular}

Table 10. Illogical pixels associated with four land cover types for the modified maps.

\begin{tabular}{ccccc}
\hline Seasons & Cropland & Forest Land & Water Body & Bare Land \\
\hline $1-2$ & $14,226,399$ & $4,053,919$ & 747,012 & 334,750 \\
$2-3$ & $21,835,662$ & $13,148,839$ & 979,944 & 189,659 \\
$3-4$ & $31,482,895$ & $10,606,269$ & $1,085,992$ & 427,656 \\
$4-1$ & $19,374,686$ & $1,370,286$ & $1,027,245$ & 294,721 \\
\hline
\end{tabular}

Figure 7 shows the illogical transitions for all seasons. Blue pixels represent the illogical transitions and white pixels represent logical transitions or no transition. Through the modified approach considering the logicality, the illogical changes have a discernible reduction in visual perspective.
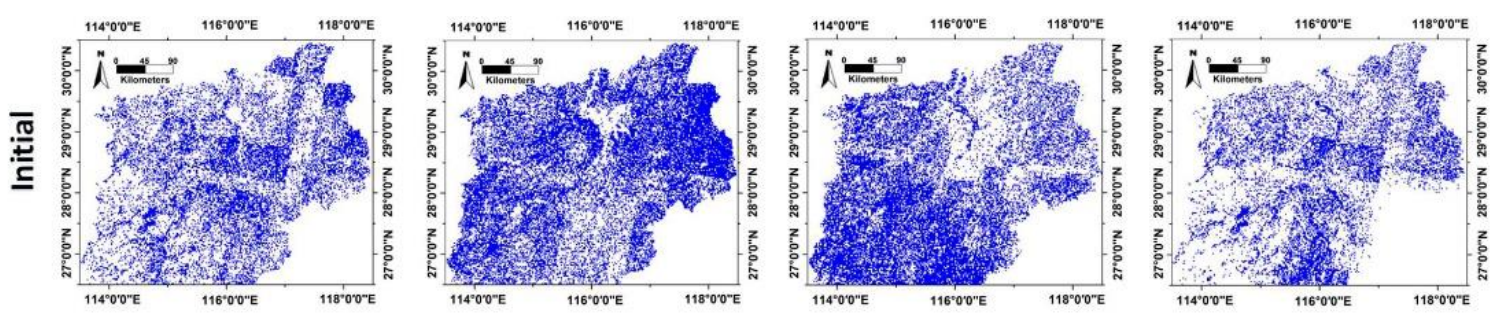

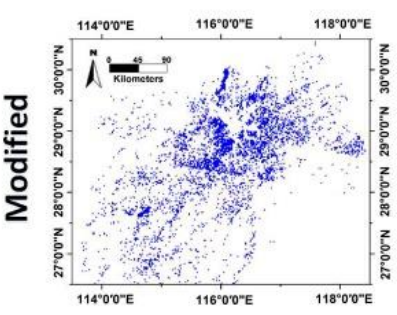

Season 1-2

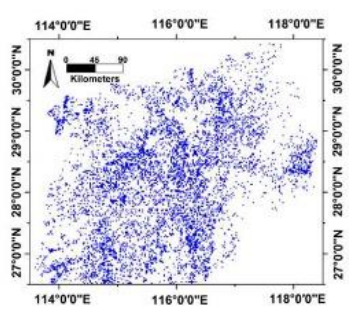

Season 2-3

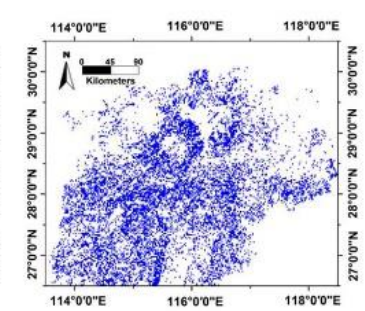

Season 3-4

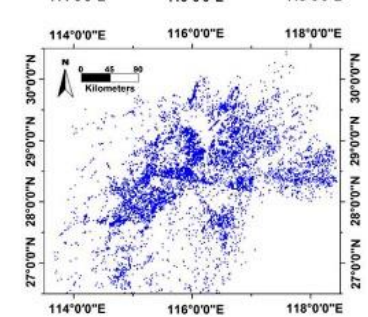

Season 4-1

Illogical transitions

Logical transitions or no transition

Figure 7. Illogical transitions before and after modification.

\subsubsection{Influence on Spatial Relationship}

The pixel-wise classification errors give rise to unexpected spatial inconsistency and discontinuity. The resultant class labels of these pixels tend to have lower average accuracy in the time point. As a result, labels of these pixels are more likely to be modified or corrected according to the proposed strategy taking into account the classification performance. The resultant land cover maps (Figure 5) and detailed maps (Figure 6) both indicate the improvement of the spatial relationship through the approach, even without any consideration of the spatial relationship in the approach itself. However, we believe the result is reliable if a certain spatially-discontinuous pixel has the same label in all time points. In this case, the area is likely to be inherently discontinuous in the spatial neighborhood. 


\subsubsection{Dealing with Wrongly-Labeled Samples}

It is always time-consuming and difficult to obtain sufficient samples to produce land cover maps at finer resolutions for large areas. In addition, we cannot ensure all the samples are absolutely right. Wrongly-labeled samples may well lead to bad classification results [53,54]. Especially for seasonal land cover mapping, it takes a lot of time to obtain samples for every season. Instead, samples labeled at a certain location will be used in different seasons. In this case, specific cropland classes may be wrongly labeled in one or two seasons. Also, other land cover types will not be always invariable because of environmental factors and human activities. As a result, serious classification errors are likely to happen with the wrongly labeled samples. The modification procedure taking into account temporal transitions will improve the results when wrongly-labeled samples exist. According to the results in Figure 5, a number of pixels which have been initially predicted as oilseed rape are replaced by paddy in season 3 .

\subsubsection{Boundedness and Unsolved Problems}

The approach has not removed all the illogical transitions, since the rules cannot correct all the illogical transitions by the overall modification for one time.

We have to mention that the definitions of "logical" and "illogical" are based on the physical truth of the study area. So the codes may be different for other areas owing to different growth characteristics of vegetation and different geographical environment. Though the codes are predetermined, we believe it is imperative to exploit logical constraints to improve the multi-temporal land cover maps. However, when it comes to large areas, for example a wider latitude range covering multiple ecosystems, one set of codes and rules will not work well.

In seasonal land cover changes, some crop species have marked phenology, which is quite different from the inter-annual land cover changes. The proposed strategy in this study focuses on producing seasonal and regional land cover maps, since the transformational codes and ecological rules are based on properties of the species of the region.

Post-classification refinement is an important work in this study. The study focuses on the refinement by taking into account the logical transitions. However, other methods of post-classification processing have not been considered. Materials like thematic information, DEM, and municipal maps should be combined to better refine the initial products [23].

\section{Conclusions}

In this study, we have introduced a seasonal land cover mapping strategy taking into account temporal transitions. The proposed strategy aims to reduce the unphysical disagreements between neighboring seasons by modifying the initial results, so as to produce rational and accurate land cover maps. We have established a series of four-digit codes for all the land cover types according to the ecological rules in the Poyang Lake Basin area. The performance of all the land cover types for different seasons is the basis of the modification rules. With the constraints of the rules, the land cover maps for all the seasons have been modified simultaneously. As a results, the average accuracy has increased by nearly $10 \%$ for specific products after the modification procedure. The illogical rates have been significantly reduced by $13 \%-35 \%$ for different seasonal shifts. The accuracy in evaluation of land cover changes have shown great improvement when using the proposed strategy. The study has demonstrated the effectiveness of the modified hierarchical mapping strategy and the importance of imposing logical constraints on seasonal land cover maps. It is promising because: (1) it is not common to simultaneously modify the land cover maps in different time points by logical constraints and classification performance in a previous study; (2) the logical transitions are merged into the hierarchical strategy, thus providing reasonable results in different levels; (3) the logical codes are quite easy to be decide for a certain region and make great contributions to improving the seasonal land cover maps. 
As future work, we will try to find different ecological and environmental rules for different temperature zones or ecosystems so as to improve the land cover maps for larger areas. Since it is relatively easier to achieve a more accurate prediction of the classification performance by samples for regional land cover products compared with global land cover products, we will try to add the classification performance to the spatial-temporal model [35] for the post-classification process of the regional land cover mapping. Meanwhile, thematic information and GIS data should be used to better refine land cover maps in the future. In addition, the proposed strategy should be applied to long-term land cover mapping, which benefits the dynamics of land use/land cover changes and the process of sustainable urbanization considerably.

Acknowledgments: The study was funded by Multiscale Remote Sensing Data Fast Processing as Required and Key Technology in Quantitative Remote Sensing Product Produce (No. 2012AA12A304), Crop Growth Information Digital Acquisition and Analysis (No. 2013AA102401), and TGRA Forest Cover and Dynamic Change Detection Based on Time Series Remote Sensing Images (No. 2014QC018).

Author Contributions: Guang Yang is the main author who proposed the basic idea and completed the experiments. Shenghui Fang and Yuanyong Dian provided the useful suggestions on designing the approaches involved in our proposed strategy. Chuang Bi helped to complete the manuscript.

Conflicts of Interest: The authors declare no conflict of interest.

\section{References}

1. Herold, M.; Mayaux, P.; Woodcock, C.E.; Baccini, A.; Schmullius, C. Some challenges in global land cover mapping: An assessment of agreement and accuracy in existing $1 \mathrm{~km}$ datasets. Remote Sens. Environ. 2008, 112, 2538-2556. [CrossRef]

2. Roy, P.S.; Roy, A.; Joshi, P.K.; Kale, M.P.; Srivastava, V.K.; Srivastava, S.K.; Dwevidi, R.S.; Joshi, C.; Behera, M.D.; Meiyappan, P.; et al. Development of decadal (1985-1995-2005) land use and land cover database for India. Remote Sens. 2015, 7, 2401-2430. [CrossRef]

3. Treitz, P.; Rogan, J. Remote sensing for mapping and monitoring land-cover and land-use change. Prog. Plan. 2004, 61, 267-279. [CrossRef]

4. Hansen, M.C.; Potapov, P.V.; Moore, R.; Hancher, M.; Turubanova, S.A.; Tyukavina, A.; Thau, D.; Stehman, S.V.; Goetz, S.J.; Loveland, T.R.; et al. High-resolution global maps of 21st-century forest cover change. Science 2013, 342, 850-853. [CrossRef] [PubMed]

5. Loveland, T.R.; Reed, B.C.; Brown, J.F.; Ohlen, D.O.; Zhu, Z.; Yang, L.; Merchant, J.W. Development of a global land cover characteristics database and IGBP DISCover from $1 \mathrm{~km}$ AVHRR data. Int. J. Remote Sens. 2000, 21, 1303-1330. [CrossRef]

6. Bartholome, E.; Belward, A.S. GLC2000: A new approach to global land cover mapping from Earth observation data. Int. J. Remote Sens. 2005, 26, 1959-1977. [CrossRef]

7. Hansen, M.C.; Defries, R.S.; Townshend, J.R.G.; Sohlberg, R. Global land cover classification at 1 km spatial resolution using a classification tree approach. Int. J. Remote Sens. 2000, 21, 1331-1364. [CrossRef]

8. Friedl, M.A.; McIver, D.K.; Hodges, J.C.F.; Zhang, X.Y.; Muchoney, D.; Strahler, A.H.; Woodcock, C.E.; Gopal, S.; Schneider, A.; Cooper, A.; et al. Global land cover mapping from MODIS: Algorithms and early results. Remote Sens. Environ. 2002, 83, 287-302. [CrossRef]

9. Friedl, M.A.; Sulla-Menashe, D.; Tan, B.; Schneider, A.; Ramankutty, N.; Sibley, A.; Huang, X.M. MODIS collection 5 global land cover: Algorithm refinements and characterization of new datasets. Remote Sens. Environ. 2010, 114, 168-182. [CrossRef]

10. Arino, O.; Bicheron, P.; Achard, F.; Latham, J.; Witt, R.; Weber, J.L. Globcover the most detailed portrait of Earth. ESA Bull. Eur. Space Agency 2008, 136, 24-31.

11. Jung, M.; Henkel, K.; Herold, M.; Churkina, G. Exploiting synergies of global land cover products for carbon cycle modeling. Remote Sens. Environ. 2006, 101, 534-553. [CrossRef]

12. Bicheron, P.; Leroy, M. Bidirectional reflectance distribution function signatures of major biomes observed from space. J. Geophys. Res. Atmos. 2000, 105, 26669-26681. [CrossRef]

13. Conant, R.T.; Paustian, K. Potential soil carbon sequestration in overgrazed grassland ecosystems. Glob. Biogeochem. Cycles 2002, 16. [CrossRef] 
14. Wu, W.; Shibasaki, R.; Yang, P.; Ongaro, L.; Zhou, Q.; Tang, H. Validation and comparison of 1 km global land cover products in china. Int. J. Remote Sens. 2008, 29, 3769-3785. [CrossRef]

15. Peres, L.F.; DaCamara, C.C. Emissivity maps to retrieve land-surface temperature from MSG/SEVIRI. IEEE Trans. Geosci. Remote Sens. 2005, 43, 1834-1844. [CrossRef]

16. Broxton, P.D.; Zeng, X.B.; Sulla-Menashe, D.; Troch, P.A. A global land cover climatology using MODIS data. J. Appl. Meteorol. Climatol. 2014, 53, 1593-1605. [CrossRef]

17. Wilting, A.; Cord, A.; Hearn, A.J.; Hesse, D.; Mohamed, A.; Traeholdt, C.; Cheyne, S.M.; Sunarto, S.; Jayasilan, M.A.; Ross, J.; et al. Modelling the species distribution of flat-headed cats (Prionailurus planiceps), an endangered South-East Asian small felid. PLoS ONE 2010, 5, e9612. [CrossRef] [PubMed]

18. Gong, P.; Wang, J.; Yu, L.; Zhao, Y.C.; Zhao, Y.Y.; Liang, L.; Niu, Z.G.; Huang, X.M.; Fu, H.H.; Liu, S.; et al. Finer resolution observation and monitoring of global land cover: First mapping results with Landsat TM and ETM+ data. Int. J. Remote Sens. 2013, 34, 2607-2654. [CrossRef]

19. Yu, L.; Wang, J.; Clinton, N.; Xin, Q.C.; Zhong, L.H.; Chen, Y.L.; Gong, P. FROM-GC: 30 m Global cropland extent derived through multisource data integration. Int. J. Digit. Earth 2013, 6, 521-533. [CrossRef]

20. Waldner, F.; Fritz, S.; Di Gregorio, A.; Defourny, P. Mapping priorities to focus cropland mapping activities: Fitness assessment of existing global, regional and national cropland maps. Remote Sens. 2015, 7, 7959-7986. [CrossRef]

21. Boryan, C.; Yang, Z.; Mueller, R.; Craig, M. Monitoring US agriculture: The US department of agriculture, national agricultural statistics service, cropland data layer program. Geocarto Int. 2011, 26, 341-358. [CrossRef]

22. Serra, P.; Pons, X.; Sauri, D. Land-cover and land-use change in a Mediterranean landscape: A spatial analysis of driving forces integrating biophysical and human factors. Appl. Geogr. 2008, 28, 189-209. [CrossRef]

23. Dewan, A.M.; Yamaguchi, Y. Land use and land cover change in Greater Dhaka, Bangladesh: Using remote sensing to promote sustainable urbanization. Appl. Geogr. 2009, 29, 390-401. [CrossRef]

24. Byomkesh, T.; Nakagoshi, N.; Dewan, A.M. Urbanization and green space dynamics in Greater Dhaka, Bangladesh. Landsc. Ecol. Eng. 2012, 8, 45-58. [CrossRef]

25. Dewan, A.M.; Corner, R.J. The impact of land use and land cover changes on land surface temperature in a rapidly urbanizing megacity. In Proceedings of the 2012 IEEE International Geoscience and Remote Sensing Symposium, Munich, Germany, 22-27 July 2012.

26. Bai, Y.; Feng, M.; Jiang, H.; Wang, J.; Liu, Y. Validation of land cover maps in China using a sampling-based labeling approach. Remote Sens. 2015, 7, 10589-10606. [CrossRef]

27. Giri, C.; Zhu, Z.L.; Reed, B. A comparative analysis of the global land cover 2000 and MODIS land cover data sets. Remote Sens. Environ. 2005, 94, 123-132. [CrossRef]

28. Van Oort, P.A.J. Improving land cover change estimates by accounting for classification errors. Int. J. Remote Sens. 2005, 26, 3009-3024. [CrossRef]

29. Cai, S.S.; Liu, D.S. Detecting change dates from dense satellite time series using a sub-annual change detection algorithm. Remote Sens. 2015, 7, 8705-8727. [CrossRef]

30. Cai, S.S.; Liu, D.S.; Sulla-Menashe, D.; Friedl, M.A. Enhancing MODIS land cover product with a spatial-temporal modeling algorithm. Remote Sens. Environ. 2014, 147, 243-255. [CrossRef]

31. Liu, D.S.; Chun, Y.W. The effects of different classification models on error propagation in land cover change detection. Int. J. Remote Sens. 2009, 30, 5345-5364. [CrossRef]

32. Liu, H.; Zhou, Q. Accuracy analysis of remote sensing change detection by rule-based rationality evaluation with post-classification comparison. Int. J. Remote Sens. 2004, 25, 1037-1050. [CrossRef]

33. Townsend, P.A.; Helmers, D.P.; Kingdon, C.C.; McNeil, B.E.; de Beurs, K.M.; Eshleman, K.N. Changes in the extent of surface mining and reclamation in the Central Appalachians detected using a 1976-2006 Landsat time series. Remote Sens. Environ. 2009, 113, 62-72. [CrossRef]

34. Liang, D.; Zuo, Y.; Huang, L.S.; Zhao, J.L.; Teng, L.; Yang, F. Evaluation of the consistency of MODIS land cover product (MCD12Q1) based on Chinese $30 \mathrm{~m}$ globeland30 datasets: A case study in Anhui Province, China. ISPRS Int. J. Geo-Inf. 2015, 4, 2519-2541. [CrossRef]

35. Wang, J.; Zhao, Y.; Li, C.; Yu, L.; Liu, D.; Gong, P. Mapping global land cover in 2001 and 2010 with spatial-temporal consistency at $250 \mathrm{~m}$ resolution. ISPRS J. Photogramm. Remote Sens. 2015, 103, $38-47$. [CrossRef] 
36. Wehmann, A.; Liu, D. A spatial-temporal contextual Markovian kernel method for multi-temporal land cover mapping. ISPRS J. Photogramm. Remote Sens. 2015, 107, 77-89. [CrossRef]

37. Gomez, C.; White, J.C.; Wulder, M.A. Optical remotely sensed time series data for land cover classification: A review. ISPRS J. Photogramm. Remote Sens. 2016, 116, 55-72. [CrossRef]

38. Pu, R.L.; Bell, S. A protocol for improving mapping and assessing of seagrass abundance along the West Central Coast of Florida using Landsat TM and EO-1 ALI/Hyperion images. ISPRS J. Photogramm. Remote Sens. 2013, 83, 116-129. [CrossRef]

39. Lin, Y.P.; Chu, H.J.; Huang, Y.L.; Tang, C.H.; Rouhani, S. Monitoring and identification of spatiotemporal landscape changes in multiple remote sensing images by using a stratified conditional Latin hypercube sampling approach and geostatistical simulation. Environ. Monit. Assess. 2011, 177, 353-373. [CrossRef] [PubMed]

40. Camps-Valls, G.; Gomez-Chova, L.; Munoz-Mari, J.; Rojo-Alvarez, J.L.; Martinez-Ramon, M. Kernel-based framework for multitemporal and multisource remote sensing data classification and change detection. IEEE Trans. Geosci. Remote Sens. 2008, 46, 1822-1835. [CrossRef]

41. McCallum, I.; Obersteiner, M.; Nilsson, S.; Shvidenko, A. A spatial comparison of four satellite derived $1 \mathrm{~km}$ global land cover datasets. Int. J. Appl. Earth Obs. Geoinf. 2006, 8, 246-255. [CrossRef]

42. Chapelle, O.; Haffner, P.; Vapnik, V.N. Support vector machines for histogram-based image classification. IEEE Trans. Neural Netw. 1999, 10, 1055-1064. [CrossRef] [PubMed]

43. Drucker, H.; Wu, D.H.; Vapnik, V.N. Support vector machines for spam categorization. IEEE Trans. Neural Netw. 1999, 10, 1048-1054. [CrossRef] [PubMed]

44. Voisin, A.; Krylov, V.A.; Moser, G.; Serpico, S.B.; Zerubia, J. Supervised classification of multisensor and multiresolution remote sensing images with a hierarchical copula-based approach. IEEE Trans. Geosci. Remote Sens. 2014, 52, 3346-3358. [CrossRef]

45. LaFrance, M.; King, J.W.; Oakley, B.A.; Pratt, S. A comparison of top-down and bottom-up approaches to benthic habitat mapping to inform offshore wind energy development. Cont. Shelf Res. 2014, 83, $24-44$. [CrossRef]

46. Bai, S.; Matsumoto, T.; Takeuchi, Y.; Kudo, H.; Ohnishi, N. Informative patches sampling for image classification by utilizing bottom-up and top-down information. Mach. Vis. Appl. 2013, 24, 959-970. [CrossRef]

47. Dewan, A.M.; Yamaguchi, Y. Using remote sensing and GIS to detect and monitor land use and land cover change in Dhaka Metropolitan of Bangladesh during 1960-2005. Environ. Monit. Assess. 2009, 150, 237-249. [CrossRef] [PubMed]

48. Foody, G.M. Assessing the accuracy of land cover change with imperfect ground reference data. Remote Sens. Environ. 2010, 114, 2271-2285. [CrossRef]

49. Fielding, A.H.; Bell, J.F. A review of methods for the assessment of prediction errors in conservation presence/absence models. Environ. Conserv. 1997, 24, 38-49. [CrossRef]

50. Schepaschenko, D.; See, L.; Lesiv, M.; McCallum, I.; Fritz, S.; Salk, C.; Moltchanova, E.; Perger, C.; Shchepashchenko, M.; Shvidenko, A.; et al. Development of a global hybrid forest mask through the synergy of remote sensing, crowdsourcing and FAO statistics. Remote Sens. Environ. 2015, 162, 208-220. [CrossRef]

51. Kinoshita, T.; Iwao, K.; Yamagata, Y. Creation of a global land cover and a probability map through a new map integration method. Int. J. Appl. Earth Obs. Geoinf. 2014, 28, 70-77. [CrossRef]

52. Vuolo, F.; Atzberger, C. Improving land cover maps in areas of disagreement of existing products using NDVI time series of MODIS-Example for Europe. Photogramm. Fernerkund. Geoinf. 2014, 5, 393-407. [CrossRef]

53. Malossini, A.; Blanzieri, E.; Ng, R.T. Detecting potential labeling errors in microarrays by data perturbation. Bioinformatics 2006, 22, 2114-2121. [CrossRef] [PubMed]

54. Leung, Y.Y.; Chang, C.Q.; Hung, Y.S. An integrated approach for identifying wrongly labelled samples when performing classification in microarray data. PLoS ONE 2012, 7, e46700. [CrossRef] [PubMed]

(C) 2016 by the authors; licensee MDPI, Basel, Switzerland. This article is an open access article distributed under the terms and conditions of the Creative Commons Attribution (CC-BY) license (http://creativecommons.org/licenses/by/4.0/). 